\title{
Making Events Redundant: Adnominal Modification and Phases ${ }^{1}$
}

\begin{abstract}
In the last two decades, Davidson's event-argument hypothesis has become very popular in natural language semantics. This article questions that event-based analyses actually add something to our understanding of the respective phenomena: I argue that they already find their explanation in independently motivated grammatical assumptions and principles which apply to all kinds of modification. Apart from a short discussion of Davidson's original arguments in favour of his hypothesis, I address Larson's event-based account of the distinctions between stage-level vs. individual-level modification and adverbial vs. adjectival modification in the nominal domain.I argue that his analysis of the former reduces straightforwardly to the grammatical structure of the nominal phase. As for the latter, I provide reasons which motivate a redescription of the phenomenon in terms of sensitivity to descriptive content rather than events. I argue that, so described, the phenomenon can be explained in terms of interface conditions, given a phasal architecture of grammar.
\end{abstract}

Key words: events, entailment, stage-level vs. individual-level predicates, adverbial vs. adjectival modification, ontological commitments, Davidson, Larson

\section{0 . Introduction}

Davidson's (1967b) hypothesis that certain verbs have an additional argument-position for event-arguments has proven a very fruitful field of research in natural language semantics. The proposal has been extended to all kinds of verbs (Parsons 1990), to deverbal nominals, and even to expressions which, initially, do not seem to have much to do with events (Parsons 2000). This paper questions whether an analysis with the help of event-arguments does actually add much to our understanding of the respective phenomena by arguing that they are predicted given the pure grammatical structure of the

\footnotetext{
${ }^{1}$ Many thanks to Wolfram Hinzen, Alex Drummond and Andrew Woodard for useful suggestions and conversations on the topic of this paper, and to Wolfram Hinzen for detailed comments on an earlier draft.
} 
relevant expressions. It further points out some problems which seem to be due to an event-based analysis rather than the explanada themselves.

In the first section, some initial motivations for assuming event-arguments are shortly reviewed. The second section delineates in what sense many phenomena which have been taken to support the assumption of eventarguments seem to follow from independently motivated assumptions about grammatical structure-building and thus do not provide evidence for the event-argument hypothesis. The general account of modification developed there provides the background for the argument in section 4. In section 3, I turn to certain kinds of ambiguities concerning adnominal modification which have been analyzed with the help of event-arguments (Larson and Segal 1995; Larson 1998). I point out some reasons for preferring this analysis over its Montagovian competitor. However, in section 4, I argue that Larson's distinction between adjectival and adverbial modifiers should be generalized to a distinction in sensitivity to descriptive content in which event-arguments don't play a role.With the help of recent theories of grammatical phases, the distinction, so described, can furthermore be explained in terms of interface conditions. In respect to Larson's analysis of the stage-/individual-level distinction (which goes back to Chierchia 1995), I claim that it follows directly from the organization of the nominal phase as described in section 2. Section 5 concludes with some remarks about the relation between natural language, metaphysics and logic.

\section{The event-argument hypothesis}

Davidson (1967b) famously argued that action verbs do not only have two argument positions, as traditionally assumed, but that they have a third argument position for an event-argument. For Davidson, the rationale for this move mainly consists initially in entailment relations between expressions which include adverbial modifiers. Consider (1-4):

1. Shem boiledthe soup at nine o'clock in London.

2. Shem boiledthe soup at nine o'clock.

3. Shem boiledthe soup in London. 
4. Shem boiledthe soup.

(1) entails (2-4), (2) and (3) independently entail (4), but the conjunction of (2) and (3) does not entail (1): We can imagine that Shem boiledthe soup at six o'clock in London and again at nine a clock in Leeds. In this case both (2) and (3) are true, but (1) is not. Traditional first order predicate logic cannot explain this phenomenon.

However, there is a phenomenon reminiscent of (1-4) which first order predicate logic seems to account for. Consider (5-8)

5. There is a blue house in London.

6. There is a blue house.

7. There is a house in London.

8. There is a house.

The entailment relations between these sentences exactly parallel those in (14): (5) entails (6-8), (6) and (7) entail (8), but their conjunction does not entail (5). Grammatically speaking, blue and in London modify house in these sentences. However, the simplest way of capturing the facts about entailment in first order predicate logic is to abstain from these grammatical facts and to assume thatblue, house and in London are all predicates of the same variable which is then existentially closed. If, in addition, all the predicates are combined by conjunction, the implication is a mere matter of conjunction reduction. This assumption also provides a reason for why the conjunction of (6) and (7) does not entail (5): The variables are in the scope of different existential quantifiers. ${ }^{2}$ The logical form of (5) would thus be (9):

9. $\exists x[$ blue $(x) \&$ house $(x) \& i n \operatorname{London}(\mathrm{x})]$

Davidson suggested that the same strategy could be applied to adverbial modification: If we treat the adverbial modifiers at nine o'clock and in London as somehow on a pair with the main sentence Shem boiledthe soup in that we assume that all of them are predicates of the same variable and are combined with the help of conjunction, we could explain the implication with first order predicate logic and we could account for the intuition that the two cases are exactly parallel. In (1), however, the variables cannot possibly range

\footnotetext{
${ }^{2}$ A problem of this approach is that there are a number of adnominal modifiers for which some or all of the implications mentioned do not hold (see section 3).
} 
over objects traditionally perceived, since there does not seem to be a way in which Shem boiled the soup describes an object. We rather seem to be inclined to say that this is a certain kind of event. Furthermore, we can say about events that they happen at a certain time, for example at 9 o'clock, and that they happen at some place, for example in London. Thus we could theorize that, despite grammatical differences, Shem boiledthe soup, at nine $o$ 'clock and in Londonare all predicates of a variable ranging over events. And we can think of sentences (or at least certain kinds of sentences) as existential quantifications over events. The logical form of (1) would thus be (10).

10. $\exists e$ [boil(Shem, the soup, e) \& in London(e) \& at 9 o' $\operatorname{clock}(\mathrm{e})]$ In prose: There is an event $e$, such that $e$ is a boilingof the soup by Shem, $e$ happened in London and $e$ happened at 9 o'clock.

There is some further motivation for splitting up the three-place predicate Shem boiled the soup, since there are implications which our current treatment does not capture: (4) entails both (11) and (12).

11. Shem boiled.

12. The soup boiled.

It has been proposed that this implication can be captured if we make use of thematic roles, a notion originally developed in syntactic theory(Baker 1988). The logical form of (4) is then (13):

13. ヨe [boiling(e) \& AGENT(e, Shem) \& THEME(e, the soup)]

Read: 'there is an event $e$ such that $e$ is a cooking and the Agent of $e$ is Shemand the Theme of $e$ is the soup'. Agent and Theme are then taken to be two possible roles which participants of an event can play in an event. This analysis captures our intuition that, even though Shem in (11) and the soup in (12) both grammatically occupy the subject position, they play different roles in the respective sentences: Shem is the person who boils something in (11), in most cases he will keep his original temperature (as long as we are not speaking metaphorically, at least), but the soup in (12) needs to be very hot in order for this sentence to be true (again at least as long as we are not in a fictional context in which soups boilsomething else and thus take the Agent role). Splitting up the arguments of a verb into arguments of thematic predicates which are united by an event-argument has been dubbed a 'neo- 
Davidsonian' analysis by Dowty (1989). The idea goes back to a proposal by Castaneda, who commented on Davidson's paper when it was first delivered.

Davidson retains Quine's (1953) idea that an analysis which involves existential quantification creates an ontological commitment to whatever is quantified over. For him, the event-argument hypothesis thus has metaphysical implications. In retrospect, he writes: 'If an ontology of events were the only way to give a satisfactory semantic analysis of these sentences and the relations between such sentences, it would, in my opinion, provide a very strong argument for the claim that there are events' (Davidson 1993: 42). Davidson thinks of events as analogous to objects. Events are thus taken to be spatio-temporal particulars (Davidson 1969; 1970; 1971; 1985a). In his earlier work, he nonetheless takes events to be a different kind of entity than objects (Davidson 1967a), but in later work, he adopts Quine's (1960) conjecture that the difference is gradual rather than absolute (Davidson 1985b).

In the semantic literature, the event-argument hypothesis is seen as an empirical hypothesis in the sense that it has to be justified in terms of its explanatory power(Parsons 1990). In the introduction to a volume on eventsemantics, Rothstein (1998: 2-3), for example, admits that 'since the event arguments never appear as such in the sentences, the evidence [for their existence] can only be indirect. [...] The strongest evidence would be a construction that cannot be reasonably explained without positing an event argument, and a weaker argument would be a construction that can be analysed much more simply if we posit an event argument.' The implication relations and the parallelism between adjectival and adverbial modification which have been delineated in the first section are two of Davidson's three original linguistic arguments in favour of the existence of event-arguments in language. ${ }^{3}$ The third one is that we actually seem to refer to events with the help of nominalisations. Thus, in addition to sentences like (14), where for Davidson there is hidden quantification over events, we also have expressions

\footnotetext{
${ }^{3}$ Davidson also provides metaphysical arguments for the existence of events as spatiotemporal entities, which I shall ignore here. He stresses that his main argument for the existence of events always remained the case from language (Davidson 1985b).
} 
like (15) and (16). Natural languages, thus, seem to enable us to refer to events in a similar way as they allow reference to objects.

\section{Brutus murdered Caesar.}

15. Brutus' murdering Caesar

16. Brutus' murder of Caesar

Further arguments have been added by a number of linguists and philosophers. For example, (14) could be followed by This happened in 44 $B C E$. It has been argued that only events can happen - the anaphoric reference of this must thus be to an event. Moreover, a number of aspectual phenomena like the distinction between telicity and atelicity have been analyzed as involving event-arguments. In addition, Schein (1993) argues that it is not possible to analyze the relation between distributivity and cumulativity in certain sentences without neo-Davidsonian thematic separation and an event-argument which ensures the unity of the event. Finally, there have been attempts to analyze some phenomena of adnominal modification with the help of event-arguments (Larson 1998).

For many of these phenomena, alternative explanations have been developed in a Montagovian framework where events are not taken to be primitives but properties of times. If it is indeed correct that these phenomena can be modelled without the assumption of an event-argument, the assumption of the event-argument is justified to the extent to which the ontological costs of assuming it outweigh the processual costs of assuming a relatively complicated mechanism involving higher order logic. It is not clear what criteria could settle this dispute, since the losses and gains are of very different natures in the two cases. Hinzen and Reichard(2011)thus try to avoid this debate by questioning the explanatory value added by a semantic event-analysis - and the very same question could be raised in respect to its Montagovian competitor. This paper takes a similar approach towards the question. It addresses in particular aspects of adnominal modification (sections 3 and 4), which has been left unaddressed in Hinzen and Reichard (2011). In section 2, I shall briefly motivate a general approach of modification, thereby addressing some of the other phenomena that have been argued to back up event-arguments. This general picture also provides a background for the more specific discussion which follows it. 


\section{Events and the organization of grammatical phases}

It is widely recognized that there is a difference between arguments and other modifiers in natural languages. In general, it is not possible to drop arguments without causing ungrammaticality but other modifiers are mostly not obligatory. It has thus been assumed that these other modifiers are generated as adjuncts rather than as specifiers or heads. ${ }^{4} \mathrm{~A}$ related difference is that in many languages arguments receive case whereas modifiers do not. Furthermore, adjuncts in general are islands in respect to movement. But most importantly, the relevant modifiers do not change anything categorically - syntactically a modified object retains whatever properties it has had before modification. Moreover, it is striking that, from a grammatical point of view, the modified expression contains the un-modified expression as a proper part. The last two features suggest that also semantically the unmodified expression is a proper part of the modified one - any specification of the unmodified expression will be a specification of the modified expression as well; and this seems to sufficiently explain why in general the modified expression implies the unmodified expression. ${ }^{5}$ Where the facts are exactly as

\footnotetext{
${ }^{4}$ In recent theory, the adjunctive status of these modifiers has often been questioned. As a result of Kayne's (1994) antisymmetry-thesis which assimilates specifiers and adjuncts, Cinque (1999), for example, argues that the rigid order in which adverbial modifiers occur crosslinguistically can only be accounted for if we assume that they are generated as specifiers of functional projections (for a similar point about adnominal modification see Scott 2002). This, however, does not change the general observation that arguments have to be present (and in most cases overt), whereas other modifiers don't need to. Cinque's functional projections can be left unspecified. And whether they are specified or not, does in most cases not change anything categorically.

5 This is obviously only the case in non-negated environments. An odd number of negations changes an environment from downward to upward entailing and thus reverses the possible inferences. Ludlow (2002) shows that it is in principle possible to use the insights of the medieval logicians to provide a syntactic account of upward and downward entailing environments.
} 
we expect them to be, no additional theory is needed - especially in light of the fact that the event-argument hypothesis does not come without further complications. Note that the present considerations are not restricted to adverbial modification and equally apply to adnominal modification. They may, thus, be seen as the source of the parallel nature of the two domains of modification.

An analysis with the help of modern logic, and a set-theoretic interpretation thereof, in a certain way obscures these results. In set-theory, the primitive is the individual which we can either refer to or quantify over. Predicates then are analyzed as sets of individuals, intensions are analyzed as the extensions of the relevant entities in possible worlds, etc. However, in line with the remarks above, it seems to be the case that the grammar of natural languages is organized exactly the other way round. Let's consider first the nominal domain.Borer (2005a) argues that (17) has the grammatical structure given in (18):

17. these three lambs

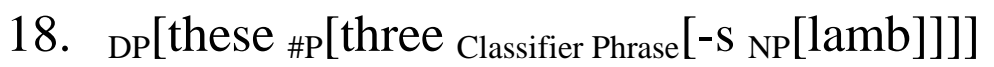

As Hinzen (2010; cf. also Hinzen 2007) explains, the most inner constituent lamb is a 'pure lamb space' which is, if it is not divided or restricted with the help of quantification, understood as a mass term, like in I ate lamb. The grammatically simplest expression thus receives a generic interpretation which is rather complicated to describe in set-theoretic terms. The classifier, which features as a separate word in some languages, for example in Chinese, divides the 'pure lamb space' into individual units. The numeral three orders these units in triples and the demonstrative determiner picks out one of these triples. It thus seems that reference to individuals is not a lexical phenomenon, but that reference to (or quantification over) individuals, which is set-theoretically primitive, is grammatically the last of several steps which the computational system of human languages can (but does not have to) take in the nominal domain. Referentiality, thus, seems to be an aspect of the meaning which grammar as opposed to the lexicon contributes. As Longobardi $(1994 ; 2005)$ argues, also proper names are grammatically not primitives but involve movement of the lexical item to the determiner position. 
A similar pattern can be found in the verbal domain (Borer 2005b). As noted above, Davidson thinks of events as spatio-temporal particulars; and this is indeed what is suggested by the event-argument hypothesis which utilizes predicate logic or set-theory, since in these domains the primitives are individuals. However, the grammatically simplest eventive expressions are generic. In contrast, to get a fully individuated event, the maximal structure available in the verbal domain is necessary.Thus, again, reference to individuals seems to be part of grammatical rather than lexical meaning. The expression coming home in (19), for example, is generic and not specified for tense. Also, destroying Syracuse in (20) is something which, in principle, many people can do at many different times; and the destruction of Syracuse in (21) can be used to pick out any such event. What all these expressions have in common, according to current syntactic theory, is that they are specified for Aspect but lack a sufficiently specified tense-projection T: the derivation of the eventive expression stops before tense is sufficiently specified. In contrast, in (22) the derivation proceeds to the T-projection and the result is a fully individuated event (for a more detailed discussion see Hinzen and Reichard 2011. They conclude form a consideration of these examples that grammar does not provide evidence for Davidson's thesis that events are temporal particulars).

19. Coming home is always wonderful.

20. Destroying Syracuse is something Caesar did.

21. The destruction of Syracuse is Caesar's deed.

22. Caesar destroyed Syracuse.

The same pattern is again found within $v \mathrm{P}$ : telic expressions have to be grammatically more complex than atelic expressions. For example, (12) lacks a sufficiently specified $v$-head, which is responsible for introducing a place for the Agent (Chomsky 1995, ch. 4). As a result, the structure in (12) cannot be telic. On the other hand, such a head is available in (4) and, since the Theme is also specified and sufficiently specific, a telic reading is possible there.The distinction between telicity and atelicity in the verbal domain is often seen as mirroring the distinction between mass and count in the nominal domain. 
In sum, considering only the few projections just discussed, the syntactic structure of (22) may be (23). The more structure is added to the left, the more specific the eventive structure becomes. In parallel to the nominal domain, quantification over fully individuated events is only the last of several steps which the grammatical derivation can (but does not have to) take. In (23), the clitic tense head attracts the verb and thus triggers movement of the verb. Caesar, first generated in the specifier position of $v$, is moved to the subject position.

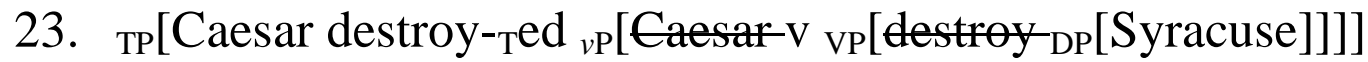

Since the expression gets the more specific the more functional structure is added to its left, it is expected that a grammatical structure implies its proper part. Thus, if I ate the lamb, I ate lamb. If I boiled the soup, the soup boiled and if Caesar destroyed Syracuse, Syracuse was destroyed. This is expected, given the grammatical structure, and a neo-Davidsonian analysis like (13) does not add to our understanding of it. Rather, the use of predicate logic and set-theory obscure this result, as it requires reference to individuals as a primitive, although, from a grammatical point of view, individuality is never a primitive or lexical phenomenon.Furthermore, it seems that reference (or quantification) itself is a phenomenon which is not primitive but only occurs at the end of the nominal or verbal phase. What is referential is the whole phrase these three lambs, not the embedded expression lamb (see section 4 for further discussion).

\section{Adnominal modifiers and events}

As has long been noted, the implicational behaviour of modifiers is not as straightforward as suggested in the first section, at least not in the nominal domain. Summarizing previous literature, Kamp and Partee (1995) distinguish between four different types of adjectives according to their inferential behaviour. First, some adjectives are intersective. A blue house, for example, is an object which is both blue and a house. If, ignoring the problems discussed in the last section, we assume that both blue and house have a set as their extension, the extension of blue house can, in line with (9), 
be described as the intersection of these two sets. Since the intersection of the two sets is a subset of both sets, the meaning of the combination of noun and adjective implies both the meaning of the noun and that of the adjective. Second, there is a kind of adjective which is similar to the first in that the combination of adjective and noun implies the noun, but that differs from the first one in that the combination of noun and adjective does not imply the adjective. A skilful surgeon, for example, may be a violinist without being a skilful violinist.Set-theoretically, the denotation of the combination can be described as a subset of the denotation of the noun. These adjectives are therefore called 'subsective'. Third, some adjectives, like alleged, do not even allow this kind of inference. An alleged murderer may not be a murderer at all. Adjectives which behave in this way are called 'nonsubsective'. Finally, some adjectives seem to negate the denotation of the noun. Thus, in some relevant sense, a fake gun is not a gun. These adjectives are called 'privative'. However, Partee (2007), in part criticising her own earlier work, has made a case for the thesis that these adjectives can also be classified as subsective.

Ignoring the rather rare case of non-subsective adjectives, Reichard (2011) argues that the distinction between intersective and subsective adjectives should not be treated as a lexical but rather as a grammatical phenomenon, since both intersective and subsective readings are systematically available for most adjectives.Furthermore, in many languages, the different readings correspond to grammatical differences. This has recently been taken as an argument for the thesis that the semantic difference corresponds to a difference in syntactic structure (Alexiadou, et al. 2007; Cinque 2010; Sproat and Shih 1988).

Two relevant ambiguities, first described in Bolinger (1967), are the distinction between individual-level and stage-level readings, which is available if the modifying adjective is deverbal (this distinction, arguably, finds a correlate for non-deverbal adjectives which give rise to kind-level and individual-level readings), and the ambiguity between adjectival and adverbial modification, which is available if the noun modified has a deverbal origin. Concerning the first ambiguity, consider (24) and (25). If visible occurs postnominally like in (24), in English, there is only one reading 
available: the stars which are currently visible. This use has been called 'stage-level' modification. The same reading is also available if visible occurs prenominally, like in (25). However, in this case, there is also an additional reading according to which those stars are referred to that are visible in general. Understood in this sense, (25) would be true, even when uttered at day time such that you couldn't currently see any star.This use has been called 'individual-level' modification(cf. Carlson 1980).

24. The stars visible include Cappella.

25. The visible stars include Cappella.

Concerning the distinction between adjectival and adverbial modification, consider (26) and (27). Again, if the modifier occurs postnominally like in (26), in English there is only one reading available. In this case beautiful modifies a person; it is thus an adjectival modifier. However, (27) is ambiguous between this reading and a reading according to which beautiful modifies not the person but the person's dancing.

26. The dancer more beautiful than her instructor

27. The beautiful dancer (Cinque 2010: Ch. 2)

The stage-level and the adjectival modification are usually taken to be intersective, whereas the individual-level and the adverbial modification are not: As noted, if visible is understood in the individual-level reading, the truth of (25) is compatible with Cappella not being (currently) visible, and if beautiful is understood in the adverbial sense, a beautiful dancer may not beso beautiful after all.

The Montagovian tradition takes intensionality to be the reason for the non-intersectivity in these cases(Clark 1970; Kamp 1975; Montague 1970; Parsons 1970; Siegel 1976). In general, adjectives are thus taken not to modify the extension but the intension of their modifee. They are, therefore, property modifiers in the sense of 'property' developed by Montague, that is, they are functions from intensions of noun phrases to such intensions of noun phrases. However, McConnell-Ginet (1982) has provided arguments which suggest that the failure of intersectivity does not need to be due to intensionality but can also be caused by a different (hidden) relationality. For example, even if we assume that everyone who cooks also eats and vice versa, Mary may cook fish without eating fish. Intuitively the failure of this 
substitution is not due to what happens in other possible worlds, but to the fact that you can cook things which you don't eat and eat things that you haven't cooked yourself in the actual world, even if you both cook and eat. Therefore, 'cooking fish and eating fish can be distinguished in a model that does not distinguish cooking and eating, with no appeal to alternative situations' (McConnell-Ginet 1982: 163). Furthermore, as McConnell-Ginet notes, in the case of adverbial modification, an appeal to possible worlds does intuitively not seem to be correct. Let's assume that the singers and dancers are coextensive. Even if this was necessarily the case, it does not follow from the fact that Mary dances beautifully that she also sings beautifully. The reason for this, therefore, cannot lie in properties which Mary has in different possible worlds, but in properties she has in the actual world. 'The explanation lies not in the existence of an alternative situation (where individuals have different properties), but simply in the possibility of a different sorting of the individuals, given a refinement of the sorting principles' (McConnell-Ginet 1982: 163).

Larson $(2002: 249 ; 1998)$ argues that in the case of adverbial modification, the reason for substitutivity failure consists in hidden relations to events: 'even if the same people sing and dance, there is a performance. And even if the same people dance and sing, the performances are still different. And one might be beautiful, and the other not.' Larson and Segal (1995) and Larson (1998) therefore suggest that the difference may be captured by assuming that expressions like dancer do not only have an argument to be taken by an object, but also an event-argument. The ambiguity between adjectival and adverbial modification can then be captured by assuming that (certain) adjectives can modify either of the two arguments. If it modifies the eventargument, we get the adverbial reading, and if it modifies the objectargument, we get the adjectival reading. Refining an analysis from his (1998), Larson (1999) suggests the logical form of the adverbial reading of (28) may be (29).

28. Olga is a beautiful dancer.

29. $\Gamma \mathrm{e}\left[[\mathrm{Con}(\mathrm{e}, \mathrm{Olga})]\left[\exists \mathrm{e}^{\prime}\left[\operatorname{overlap}\left(\mathrm{e}, \mathrm{e}^{\prime}\right) \& \operatorname{dancing}\left(\mathrm{e}^{\prime}\right) \&\right.\right.\right.$ Agent(Olga,e')]] [beautiful $(e, C)]]$ 


\section{0. $\Gamma \mathrm{e}\left[[\mathrm{Con}(\mathrm{e}, \mathrm{Olga})]\left[\exists \mathrm{e}^{\prime}\left[\operatorname{overlap}\left(\mathrm{e}, \mathrm{e}^{\prime}\right) \&\right.\right.\right.$ dancing $\left(\mathrm{e}^{\prime}\right) \&$} Agent(Olga,e')]] [beautiful(Olga, C)]]

$\Gamma$ is a generic quantifier over events (Chierchia 1995). Con(e, Olga) is the contextually determined restrictor of the generic event-quantification which ensures that Olga does not always have to dance in order to count as a dancer, but only on certain occasions. The overlap relation ensures that even on the given occasion - let's say when Olga is in clubs - she does not necessarily always dance; she only is asserted to dance at some times during these events. That Olga is the Agent of such events of dancing which overlap with a generic event makes Olga a dancer. What is important for our purposes is that beautiful now is a predicate of the generic event (relative to the context C) - it does not modify Olga directly. In contrast, if beautiful receives an adjectival interpretation, it is a predicate of Olga, as illustrated in (30). According to this proposal the reason for the ambiguity does now not lie in the adjective but in the noun. Note that according to this theory, both readings are extensional.

Event semantics can also be used for explaining the difference between the stage-level and the individual-level readings. As Chierchia (1995) notes, individual-level modifiers are inherently generics while stage-level modifiers are not. In Larson's theory, the difference between them thus turnsout to be a difference in the quantifier over event-variables. Whereas individual-level predicates are in the scope of the generic quantifier of the event they modify, stage-level predicates are not. ${ }^{6}$

As in the case of the adjectival/adverbial distinction, this move has some intuitive plausibility, since,again, the alternative doesn't:it does not seem to be the case that the stage-/individual-level distinction is a phenomenon which has something to do with intensionality. It is not even clear that there is an inference failure between visible star (where visible has an individual-level reading)and visible - a visible (in the individual-level reading) star is a subset of things which are generally visible. Thus, as Bolinger (1967) originally

\footnotetext{
${ }^{6}$ It seems that this analysis could be extended to the dichotomy between kind-level and individual-level modifiers discussed in Reichard(2011), which similarly seems to be a difference between genericity and individuality - the only difference then is that the relevant quantifiers will in these cases scope over objects, not events.
} 
proposed, individual-level and stage-level predicates seem to designate different kinds of properties, and an object can be visible in one sense and fail to be visible in the other. This has nothing to do with properties which the object has in different possible worlds, but with different properties the object has in this world.

A further strength of Larson's analysis is that it offers different treatments for the stage-level/individual-level ambiguity and for the adjectival/adverbial ambiguity. That different treatments are necessary is suggested by two facts about their distribution. First, whereas the adverbial reading cannot occur in predicate position, the individual-level reading can. ${ }^{7}$ Thus, there is no adverbial reading available in (31), but there is an individual-level reading in (32).

31. The dancer is beautiful.

32. The Danube is navigable.

Furthermore, it seems that the two phenomena can in principle co-occur. Thus, arguably, there are four possible readings for (33). First, responsible may be used as an adverbial modifier. In this case, the dancer, let's call her $\mathrm{A}$, is not necessarily a responsible person in everyday life, but she is responsible for the dance - she may, for example, be leading the dance. At the same time, responsible may be used as an individual-level or as a stagelevel predicate. On the adverbial individual-level reading, our dancer is usually responsible for leading the dance, but may currently be on holiday and not be dancing at all. During this time, a second dancer, let's call her B, may take over A's job. For B, being responsible is an adverbial stage-level predicate. However, responsible may also be used adjectival. In that case, the dancer, $\mathrm{C}$, may or may not be responsible for the dancing, but is generally behaving in a responsible way $-\mathrm{C}$ helps children and elderly people crossing the street, cycles to work rather than using a car, and does whatever you think responsible people do. This in turn may be a stage-level or an individual-level predicate: A dancer may behave responsibly in general, but perhaps not at the moment of your assertion, or be usually irresponsible, but doing a great job at

7 Judgments about the latter seem to differ - ironically, Larson (1999) claims that individual-level readings cannot occur in predicate position. 
the moment regarding responsibility. On the other hand, if responsible appears post-nominally as in (34), only the adjectival, stage-level reading is available. The independence of the two phenomena is supported by the fact that when responsible appears twice prenominally, the first can, for example, have an adjectival individual-level reading: a person who is generally responsible; and the second an adverbial stage-level reading: someone responsible for tonight's dancing. Thus, neither of the two occurrences of responsible is fully intersective in the sense of Kamp and Partee (1995). To get a fully intersective reading in this sense, the adjective has to have both, a stage-level and an adjectival reading.

33. A responsible dancer

34. A dancer responsible for the tickets

35. I need a responsible responsible dancer for tonight's show.

\section{Adnominal modification, grammatical organization, and the interface}

In this section, I first argue that the analysis which Larson provides for the stage-/individual-level distinction reduces to the grammatical structure of the DP, described in section 2. Then I turn again to the adjectival/adverbial modification distinction. Here, I argue that even though Larson's theory seems to capture the phenomenon in some respects better than the Montagovian alternative, there seem to remain some problems. First, there is the intuition that even when someone asserts (28) in the adverbial reading, it is still Olga who is said to be beautiful, not her dancing. Second, there are problemscreated by describing the phenomenon with the help of eventarguments, as this description does not capture central aspects of the linguistic phenomena. Third, given a more suitable description of the phenomenon, it seems to follow from the phasal organisation of language.

Larson analyzes the difference between stage-level and individual-level predicates in terms of a difference between generic and existential quantification over event-arguments. He notes that crosslinguistically the 
individual-level modifier is always closer to the noun than the stage-level modifier. Thus if, in English, visible occurs twice in front of a noun, the first (counted from left to right) has the stage-level and the second the individuallevel reading like in (36). These facts are captured if the generic quantifier, which binds all the open event-arguments in its scope, has a relatively narrow scope, as exemplified in (37) (based on Larson 1998, example 24).

36. The visible visible stars include Cappella.

37. $\left[\begin{array}{lll}\mathrm{AP} & {\left[\Gamma \mathrm{e}\left[\begin{array}{cc}\mathrm{AP} & \mathrm{N}\end{array}\right]^{8}\right] \quad \mathrm{AP}}\end{array}\right]$

It has to be noted, though, that this is mainly a redescription of the phenomena in logical terms which independently follows from the grammatical structure of the nominal phase. As discussed in section 2, a bare nominal will have a generic interpretation. Structure and individuality is gained only with the help of a number of functional heads. A modifier will modify whatever it is attached to. And if, as Larson shows, the individuallevel modifier is closer to the noun than the stage-level modifier, it is expected that the latterwill exhibit more individuality than the latter (at least as long as there are relevant intermitting functional projections).

Let's turn to Larson's explanation of the adjectival/adverbial modification. Larson $(1998 ; 1999)$ provides two paraphrases for the adverbial reading of (28) given in (38) and (39).

38. Olga is beautiful as a dancer.

39. Olga dances beautifully.

The two paraphrases seem to differ in meaning only slightly but in an important way. In (38), we predicate something of Olga - as noted above (cf. 31 ), the adverbial reading is generally accepted not to be available in predicate position. Beautiful in (38) should thus not be a predicate of an event but a predicate of an object in Larson's terms. In contrast, in (39) beautifully is a proper adverb and modifies a verb. According to Davidson's eventargument hypothesis, it thus is a predicate of an event. Larson's analysis of the phenomenon presupposes (39), understood as a generic sentence, as the

\footnotetext{
${ }^{8}$ This is the place for postnominal individual-level modifiers which we find, for example, in Romance languages (cf. Cinque 2010).
} 
correct paraphrase of (28) when he analyzes adverbially used adjectives as generic event modifiers. However, (38) seems to be a much better paraphrase of (28) than (39). Even if we assert (28) using beautiful in the adverbial meaning, we do not say that Olga's dancing is beautiful, but that Olga herselfis when she dances. Further evidence for this claim comes from examples like (40) which, according to Larson's theory, should have (41) as a paraphrase. However, the pure adverbial reading in this sense does not seem to be readily available here. Nonetheless, when someone asserts (40), we would naturally think of Olga as singing beautifully as well. Indeed, if we knew that she did not, (40) would in most circumstances sound ironic.

40. Olga is a beautiful singer.

41. Olga sings beautifully.

This suggests that the adverbial reading of an adjective, after all, does not seem to modify an underlying event. ${ }^{9}$ The difference rather seems to be that an adverbial adnominal modifier is sensitive to the descriptive content of its modifee in a way in which the adjectival modifier is not. Whereas the adverbial modifier modifies its host under a description, the adjectival modifier modifies the referent of the nominal phrase it attaches to irrespective of its descriptive content. According to this picture, the difference between the adverbial and the adjectival readingsthus turns out to be a difference in sensitivity to the descriptive content of the modifee. ${ }^{10}$

\footnotetext{
${ }^{9}$ A further argument towards this conclusion is provided by Szabo (2001). He argues that events on their own are not sufficient for a proper analysis of adverbial modification. He asks us to imagine a possible world where dances are only performed in order to persuade the gods to let it rain. It seems that in such a world the rain-making events would be the same events as the dancing-events. Nonetheless, someone may be a good dancer but not a good rainmaker if she has perfected her dancing technically to a high degree but is nonetheless not very successful in making rain. Szabo's solution is to assume a contextual variable which specifies the respect in which something is called good; the same strategy could be used for other adjectives like beautiful. However, Szabo's challenge is also met by the proposal informally discussed in the remainder of this section. This proposal, furthermore, avoids postulating contextual variables which solve the problem by stipulation rather than explanation.

${ }^{10}$ For anyone who does not accept this analysis, there is, of course, a fallback position which simply syntactizises the semantic account. It might thus be argued that the
} 
A virtue of this analysis is that it can accommodatesome examples which have been taken to be problematic for Larson. Arguably, the event-argument is due to the verbal origin of the noun. Thus, (42) owes its adverbial reading to the fact that we could also say that the referent rules justly. But what about (43)? There does not seem to be a verb to king. As Larson (1999)admits, there are a number of examples like this, and it does not seem to be convincing to assume that there are event-arguments hidden in manyof the most common nouns which do not seem to have anything to do with events. ${ }^{11}$

42. The just ruler

43. The just king(Vendler 1968: 91)

To recapitulate, we have seen that the adverbial reading is unavailable in predicative position (cf. 31). In English, it is also unavailable in postnominal position (cf. 24). In prenominal position, both the adverbial and the adjectival readings are available. However, even in prenominal position, there is a difference in that if the same adjective occurs in both the adjectival and the adverbial reading, the adjective with the adverbial reading is closer to the noun than the one with adjectival reading: In (44), the first occurrence of heavy (from left to right) can be understood as heavy in the sense of weight and the second as meaning that John smokes a lot, but not vice versa.

44. John is a heavy heavy smoker.

If the phenomenon is correctly described in terms of sensitivity to the descriptive content of the modifee, then it seems that descriptive content is only available relatively close to the noun but unavailable further away. And indeed, the notion of a grammatical phase seems to provide an explanation of the unavailability of descriptive content at least for the predicate position and (in Germanic languages) the postnominal position: Chomsky (2001; 2008) proposes that grammatical structure is derived in units which he calls 'phases'. Grammatical evidence for their existence is mainly provided by island conditions, that is, grammatical structure becomes unavailable for the further derivation at some point. The hypothesis is that at these points, the

availability of the adverbial modification is due to the verbal origin of the noun. Examples like (43) could then be taken as cases of reconstruction.

${ }^{11}$ Vendler (1968: 92) mentions fast horse, slow car, careful scientist, good poet and good father as further examples of the same phenomenon. 
complex syntactic object is spelled out and receives an interpretation. A rationale for this hypothesis is that a derivation in phases reduces the computational burden - when the phase is finished, the complex structure is gone from the derivational workspace and only the non-complex referent derived in the phase is left. If this is correct, it follows that the further derivation is insensitive to the descriptive content of the referents generated so far.

Our redescription of the difference between adverbial and adjectival adjectives seems to perfectly match this prediction of the phasal architecture of language: To the extent to which we do not cross phase-boundaries in cases where descriptive content is available and do cross phase-boundaries where it is not, grammatical phases can be taken to explain the difference in meaning between adverbial and adjectival adnominal modifiers. Indeed, if DP is a phase, ${ }^{12}$ it follows that its descriptive content is unavailable in the predicate position. It also seems that relevant postnominal modification in English, which has to be phrasal in order to be licensed, attaches in a separate phase: more beautiful than her instructor in (26) is even phonologically detached from its modifee. In respect to the prenominal position, it seems that the adverbial reading is the most salient one (so much so that Bolinger 1967 argued that the adjectival reading is not available in this position). And this is predicted, given the fact that the modifier modifies an object under a certain description; that is, given the fact that there is still grammatical structure available at the time of modification. In contrast, the event-analysis does not predict this preference here. However, structure can also be ignored, hence the availability of the more paratactic adjectival reading even in this position. Note that a purely adjectival reading is rather marginal: in fact, it only seems to be available in cases involving movement-phenomena like focus. Thus, apart from ironic statements, we may use the beautiful dancer to refer to a person who dances dreadfully, only in contrast to someone who, in addition, looks ugly too. ${ }^{13}$

${ }^{12}$ Chomsky originally proposed that only $\mathrm{CP}$ and $v \mathrm{P}$ are phases. However, DP has been added to the list in many more recent proposals (cf. Chomsky 2007).

13 The latter observation may suggest that also in the prenominal position there is a grammatical difference between the two readings. However, it is not clear whether the 


\section{Conclusion}

In sum, it has been argued that the phenomena which have been taken to support the event-argument hypothesis find their explanation in mainly grammatical terms. Thus the fact that, ceteris paribus, an expression modified adverbially entails its non-modified counterpart is expected given the general structure in which grammatical meaning is computed and the fact that the verb-phrase of the latter is a proper part of the verb-phrase of the former. The parallel nature of adnominal and adverbial modification finds a natural explanation in the grammatical fact that modification seems to work in similar ways across all grammatical domains. And the phenomena which originally motivated the neo-Davidsonian approach can be accounted for with a standard syntactic verb-shell analysis(for a more detailed discussion of these and other phenomena see Hinzen and Reichard 2011). Also the stage/individual-level distinction, when analyzed as a phenomenon about genericity, seems to directly follow from the structure of the grammatical phase. Finally, it has been argued that Larson's analysis of the adjectival/adverbial modification distinction, even though it captures some phenomena more adequately than the traditional Montagovian account,

phasal explanation can get away without 'undoing' structure, since, even though the focused modifiers occupy higher nodes in the grammatical structure than unfocused ones, they are still taken to belong to the same phase.

There is an alternative explanation for the ambiguity of prenominal adjectives explored in Reichard (2011). The readings of adjectives which Kamp and Partee (1995) classify as intersective (and this includes adjectival readings) have recently been argued to originate in a reduced relative clause whilst the readings of adjectives classified as subsective are taken to have no clausal origin (Alexiadou, et al. 2007; Cinque 2010). Given the assumption that CPs are phases in the relevant sense, the descriptive content of the adjective cannot be modified relative to the modifee in the case of the clausal origin, whereas this possibility is open for non-clausal modifiers. A problem for this proposal in respect to the adverbial/adjectival modifier distinction is that it does not seem to be the descriptive content of the modifier the availability of which seems to matter, but the availability of the descriptive content of the modifee. 
should be refined: rather than assuming the nominal to have a position for an event-argument in addition to the one forthe objective argument, the phenomenon should be described in terms of sensitivity to the descriptive content of the modifee. The adverbial reading then is due to such sensitivity. A phasal account of grammar predicts that this reading is unavailable in predicative and, in the case of English, in postnominal position. We can conclude from this that the assumption of event-arguments does not add anything to our understanding of the relevant phenomena, given that they find their explanation in independently motivated grammatical principles.This does not mean that the hypothesis is incompatible with the phenomena described. But rather than adding to their explanation, an account based on event-arguments seems to add further problems which have to be cared of.

As noted, Davidson thought of his event-argument hypothesis as the core evidence for a metaphysical thesis concerning the existence and particularity of events in a metaphysical sense. However, if the position defended here is correct, the event-argument hypothesis does not find independent support as far as the linguistic phenomena are concerned, the metaphysical theses thus remains in want of support from natural language.

The fact that grammatical principles seem to provide an explanation for why certain kinds of expressions have a certain meaning does furthermore suggest that grammar is not only a way of encoding meaning, but is part of the creation of meaning; we can, thus, speak of something like 'grammatical meaning' as opposed to different aspects of meaning (for example lexical meaning). Whether something is picked out as an event, object or proposition, whether it is described as exhibiting generality or individuality, then, seems to be part of this grammatical meaning. This provides another argument against the validity of using ontological commitments in respect to natural language to back up metaphysical theses. The ontological categories we find in natural languages seem to be part of how we refer to the world using grammatical structures rather than categories of the world which are independent of grammar.

Finally, the event-argument hypothesis seems to be a case in point where additional problems are introduced by the analysis of the phenomena. As 
noted in the second section, this problem is not restricted to event-semantics but extends to other uses of logic in the analysis of natural languages, since the structure of its common set-theoretical interpretation at least seems to differ radically from the organisation of natural language. This is not surprising, given that logical systems were initially developed for very different purposes. But we should, therefore, be very sensitive to whether, and in what sense, they provide an adequate analysis of natural language, whenusing them for this purpose.

\section{References}

Alexiadou, A., L. Haegeman and M. Stavrou 2007. Nouns Phrase in the Generative Perspective. Berlin: Mouton de Gruyter.

Baker, M. 1988. Incorporation. Chicago: University of Chicago Press.

Bolinger, D. 1967. Adjectives in English: Attribution and Predication. Lingua 18, 1-34.

Borer, H. 2005a. In Name Only. Oxford: OUP.

Borer, H. 2005b. The Normal Course of Events. Oxford: OUP.

Carlson, G. 1980. Reference to Kinds in English. New York: Garland.

Chierchia, G. 1995. Individual-Level Predicates as Inherent Generics. In: The Generic Book, ed. by G. Carlson and F. J. Pelletier, 176-223. Chicago: University of Chicago Press.

Chomsky, N. 1995. The Minimalist Programme. Cambridge, MA: MIT Press.

Chomsky, N. 2001. Derivation by Phrase. In: Ken Hale. A Life in Language, ed. by M. Kenstowicz, 1-52. Cambridge, MA: MIT Press.

Chomsky, N. 2007. Approaching UG from below. In: Interfaces + Recursion $=$ Language? Chomsky's Minimalism and the View from Syntax-Semantics, ed. by U. Sauerland and H.-M. Gärtner, 1-29. Berlin: Mouton de Gruyter.

Chomsky, N. 2008. On Phases. In: Foundational Issues in Linguistic Theory: Essays in Honor of Jean-Roger Vergnaud, ed. by R. Freidin, C. P. Otero and M. L. Zubizarreta, 133-66. Cambridge MA: MIT Press.

Cinque, G. 1999. Adverbs and Functional Heads: A Cross-linguistic Perspective. Oxford: OUP.

Cinque, G. 2010. The Syntax of Adjectives: A Comparative Study. Cambridge MA: MIT Press.

Clark, R. 1970. Concerning the Logic of Predicate Modifiers. Nous 4, 311-35.

Davidson, D. 1967a. Causal Relations. In: Essays on Actions and Events, 149-62. Oxford: Oxford University Press (2001).

Davidson, D. 1967b. The Logical Form of Action Sentences. In: Essays on Actions and Events, 105-22. Oxford: Oxford University Press (2001). 
Davidson, D. 1969. The Individuation of Events. In: Essays on Actions and Events, 16380. Oxford: Oxford University Press (2001).

Davidson, D. 1970. Events as Particulars. In: Essays on Actions and Events, 181-88. Oxford: Oxford University Press (2001).

Davidson, D. 1971. Eternal vs. Ephemeral Events. In: Essays on Actions and Events, 189203. Oxford: Oxford University Press (2001).

Davidson, D. 1985a. Adverbs of Actions. In: Essays on Actions and Events, 293-304. Oxford: Oxford University Press (2001).

Davidson, D. 1985b. Reply to Quine on Events. Appendix B. In: Essays on Actions and Events, 305-11. Oxford: Oxford University Press (2001).

Davidson, D. 1993. Method and Metaphysics. In: Truth, Language, and History, 39-45. Oxford: OUP (2005).

Dowty, D. R. 1989. On the Semantic Content of the Notion of 'Thematic Role'. In: Properties, Types, and Meaning. Vol. II: Semantic Issues, ed. by G. Chierchia, B. H. Partee and R. Turner, 69-129. Dordrecht: Kluwer.

Hinzen, W. 2007. An Essay on Names and Truth. New York: Oxford University Press.

Hinzen, W. 2010. An Argument Against Compositionality. manuscript.

Hinzen, W. and U. Reichard 2011. The Event-Argument Hypothesis: In Search of Evidence. manuscript.

Kamp, H. 1975. Two Theories about Adjectives. In: Formal Semantics of Natural Language, ed. by E. L. Keenan, 123-55. Cambridge: CUP.

Kamp, H. and B. H. Partee 1995. Prototype Theory and Compositionality. Cognition 57, 129-91.

Kayne, R. 1994. The Antisymmetry of Syntax. Cambridge, MA: MIT Press.

Larson, R. K. 1998. Events and Modification in Nominals. In: Semantics and Linguistic Theory VIII (SALT8), ed. by D. Stolovitch and A. Lawson, 145-68. Ithaka, NY: Cornell University.

Larson, R. K. 1999. The Semantics of Adjectival Modification. Delivered at the Duch National Graduate School (LOT), Amsterdam. http://semlab5.sbs.sunysb.edu/ rlarson/LOT(99)/Contents.htmld/index.html.

Larson, R. K. 2002. The Grammar of Intensionality. In: Logical Form and Language, ed. by G. Preyer and G. Peter, 228-62. Oxford: Clarendon.

Larson, R. K. and G. Segal 1995. Knowledge of Meaning: An Introduction to Semantic Theory. Cambridge, MA: MIT Press.

Longobardi, G. 1994. Reference and Proper Names. A Theory of N-Movement in Syntax and Logical Form. Linguistic Inquiry 25, 609-65.

Longobardi, G. 2005. Towards a Unified Grammar of Reference. Zeitschrift für Sprachwissenschaft 24, 5-44.

Ludlow, P. 2002. LF and Natural Logic. In: Logical Form and Language, ed. by G. Preyer and G. Peter, 132-68. Oxford: Clarendon.

McConnell-Ginet, S. 1982. Adverbs and Logical Form: A Linguistically Realistic Theory. Language 58, 144-84. 
Montague, R. 1970. English as a Formal Language. In: Formal Philosophy: Selected Papers of Richard Montague, ed. by R. H. Thomason, 189-224. New Haven: Yale University Press (1974).

Parsons, T. 1970. Some Problems Concerning the Logic of Grammatical Modifiers. Synthese 21, 320-34.

Parsons, T. 1990. Events in the Semantics of English: A Study in Subatomic Semantics. Cambridge, MA: MIT Press.

Parsons, T. 2000. Underlying States and Time Travel. In: Speaking of Events, ed. by J. Higginbotham, F. Pianesi and A. C. Varzi, 81-93. Oxford: OUP.

Partee, B. H. 2007. Compositionality and Coercion in Semantics: The Dynamics of Adjective Meaning. In: Cognitive Foundations of Interpretation, ed. by G. Bouma, I. Krämer and J. Zwarts, 145-61. Amsterdam: Royal Netherlands Academy of Arts and Sciences.

Quine, W. v. O. 1953. On What There Is. In: From a Logical Point of View: LogicoPhilosophical Essays, 1-19. New York: Harper \& Row (1963).

Quine, W. v. O. 1960. Word and Object. Cambridge, MA: MIT Press (1993).

Reichard, U. 2011. Inference and Grammar: Intersectivity, Subsectivity and Phases. To appear in Proceedings of the Irish Network in Formal Lingusitics Conference 2011. Belfast Workingpapers in Linguistics.

Rothstein, S. 1998. Introduction. In: Events and Grammar, ed. by S. Rothstein, 6-11. Dordrecht: Kluwer.

Schein, B. 1993. Plurals and Events. Cambridge MA: MIT Press.

Scott, G.-J. 2002. Stacked Adjectival Modification and the Structure of the Nominal Phrases. In: Functional Structure in DP and IP, ed. by G. Cinque, 91-120. New York: OUP.

Siegel, M. E. A. 1976. Capturing the Adjective. University of Massachusetts, Amherst, MA.

Sproat, R. and C. Shih 1988. Prenominal Adjectival Ordering in English and Mandarin. In: Proceedings of NELS 18, ed. by J. Blevins and J. Carter, 465-89. Amherst: GSLA.

Szabò, Z. G. 2001. Adjectives in Context. In: Perspectives on Semantics, Pragmatics, and Discourse, ed. by R. Harnish and I. Kenesei, 119-46. Amsterdam: John Benjamins.

Vendler, Z. 1968. Adjectives and Nominalisations. The Hague: Mouton. 